\title{
A test of the utility of DNA barcoding in the radiation of the freshwater stingray genus Potamotrygon (Potamotrygonidae, Myliobatiformes)
}

\author{
Daniel Toffoli ${ }^{1}$, Tomas Hrbek ${ }^{1,2}$, Maria Lúcia Góes de Araújo ${ }^{3}$, Maurício Pinto de Almeida ${ }^{4}$, \\ Patricia Charvet-Almeida ${ }^{5}$ and Izeni Pires Farias ${ }^{1}$ \\ ${ }^{1}$ Laboratório de Evolução e Genética Animal, Departamento de Ciências Biológicas, \\ Universidade Federal do Amazonas, Manaus, AM, Brazil. \\ ${ }^{2}$ Biology Department, University of Puerto Rico, Rio Piedras, San Juan, Puerto Rico. \\ ${ }^{3}$ Laboratório de Histologia, Departamento de Morfologia, Universidade Federal do Amazonas, \\ Manaus, AM, Brazil. \\ ${ }^{4}$ Museu Paraense Emílio Goeldi, Universidade Federal do Pará, PA, Brazil. \\ ${ }^{5}$ Departamento de Sistemática e Ecologia, Universidade Federal da Paraíba, João Pessoa, PB, Brazil.
}

\begin{abstract}
DNA barcoding is a recently proposed global standard in taxonomy based on DNA sequences. The two main goals of DNA barcoding methodology are assignment of specimens to a species and discovery of new species. There are two main underlying assumptions: i) reciprocal monophyly of species, and ii) intraspecific divergence is always less than interspecific divergence. Here we present a phylogenetic analysis of the family Potamotrygonidae based on mitochondrial cytochrome $c$ oxidase I gene, sampling 10 out of the 18 to 20 valid species including two non-described species. Potamotrygonidae systematics is still not fully resolved with several still-to-be-described species while some other species are difficult to delimit due to overlap in morphological characters and because of sharing a complex color patterns. Our results suggest that the family passed through a process of rapid speciation and that the species Potamotrygon motoro, $P$. scobina, and $P$. orbignyi share haplotypes extensively. Our results suggest that systems of identification of specimens based on DNA sequences, together with morphological and/or ecological characters, can aid taxonomic studies, but delimitation of new species based on threshold values of genetic distances are overly simplistic and misleading.
\end{abstract}

Key words: Potamotrygon, barcoding, radiation, phylogenetics, COI, mtDNA.

Received: October 20, 2006; Accepted: May 22, 2007.

\section{Introduction}

The Consortium for the Barcode of Life was created in order to develop DNA barcoding as a global standard (http://barcoding.si.edu). The objective of DNA barcoding is the use of one or more genes to $i$ ) assign unknown specimens to its species, and ii) increase the discovery of new species (Moritz and Cicero, 2004). The proponents of barcoding argue that there exists an overwhelming number of undescribed species and the number of traditional taxonomists is too few to handle this diversity; morphologically cryptic species are overlooked by traditional morphological methods; and larval stages of some species groups often

Send correspondence to Izeni Pires Farias. Laboratório de Evolução e Genética Animal, Departamento de Ciências Biológicas, Universidade Federal do Amazonas, Mini Campus ICB, Av. Gen. Rodrigo Octávio Jordão Ramos 3000, 69077-000 Manaus, AM, Brazil. E-mail: izeni_farias@ufam.edu.br. cannot be assigned to the correct species based on morphology (Hebert et al., 2003). The DNA barcoding supposedly would be a fast, efficient, and globally accessible method for delimiting and identifying new species (Hebert et al., 2003). The mitochondrial gene cytochrome $c$ oxidase I (COI) was chosen as the standard gene for DNA barcoding because it shows a conserved amino acid sequence that facilitates the design of universal primers applicable to a diverse group of organisms; COI also apparently functions well to discriminate species (Hebert et al., 2003, 2004; Ward et al., 2005; Hajibabaei et al., 2006).

There are two basic assumptions that underpin DNA barcoding methodology; 1) monophyly of species with respect of the molecular marker used, and 2) intraspecific genetic divergence is much smaller than genetic differences among species, thus justifying the use of divergence thresholds to assign individuals to correct species based on genetic divergence. In a seminal publication on barcoding, 
Hebert et al. (2004) found in a survey of 260 North American bird species that COI divergences among close relatives were on average 18 times higher than intraspecific divergences. The authors proposed a 10x threshold divergence between clades to within clades as a way to accelerate the discovery of new species, i.e. divergences over the 10x threshold most likely represent divergences among species rather than within species. Using this approach Hebert et al. (2004) identified four possible new species of birds nesting in North America. Hajibabaei et al. (2006) found distinct COI barcodes for $97.9 \%$ out of 521 lepidopteran species surveyed in Costa Rica, albeit no threshold value was proposed to assign specimens to described species or to identify new species, an important component of barcoding.

However, critics of DNA barcoding argue that many of the barcoding studies do not compare sister species, the primary candidates to share haplotypes and to show low interspecific divergence. Additionally, because these studies do not sample diversity within the geographical distribution of the species, i.e. they are typological in character, current DNA barcoding studies tend to underestimate intraspecific genetic variability (Moritz and Cicero, 2004). Indeed, Johnson and Cicero (2004) found results that sharply contrast those of Hebert et al. (2004) when comparing sister species of birds from North America. They found average interspecific genetic values much lower and intraspecific genetic variability much higher than those found by Hebert et al. (2004), and they also found many cases of paraphyly.

In the present study we test the efficiency of the mitochondrial gene COI for delimiting species of freshwater stingrays of the family Potamotrygonidae, using the methodology proposed by the DNA barcoding consortium. The family Potamotrygonidae is currently composed of three genera, Paratrygon Duméril, 1865, Plesiotrygon Rosa, Castello and Thorson, 1987, and Potamotrygon Garman, 1877. The first two genera are considered monotypic while Potamotrygon contains 16 (Carvalho et al., 2003) to 18 (Rosa, 1985) taxonomically valid species. However, the taxonomy of the family is not well resolved with some species being considered taxonomically dubious, and several species yet to be described (Carvalho et al., 2003).

Earliest taxonomic recognition of potamotrygonid stingrays dates to the colonial period (Castex et al., 1963 and references therein); however, it was not until the 1960's and 1970's that taxonomist became interested in this group. Studies from this period were based on few individuals (e.g. Castex et al., 1963; Castex, 1964; Achenbach and Achenbach, 1976) and were unable to encompass the phenotypic variation observed in nature. Rosa (1985) provided the first taxonomic revision of the family, generating the first genus-level phylogenetic hypothesis. Rosa (1985) also produced a species key for the Potamotrygonidae; the key was based primarily on coloration patterns, although his study relied primarily on specimens already deposited in museums. We used the key of Rosa (1985) and characters in original descriptions to classify our specimens.

Starting in the late 1990's, several groups of researchers initiated field studies and collections in the Amazon basin focusing particularly on the Negro River (Araújo, 1998), the Amazon River (Charvet-Almeida, 2004), especially its mouth and lower portion (Charvet-Almeida, 2001; Almeida, 2003), the Xingu River (Charvet-Almeida, 2006) and Tocantins River (Rincon, 2006). These studies resulted in the discovery of new and what appear to be new species, but also demonstrated very high degrees of polychromatism in some species pointing out the difficulty of delimiting species using the key proposed by Rosa (1985). An especially high degree of polychromatism was observed in Potamotrygon motoro and Potamotrygon orbignyi in the Negro River (Araújo, 1998), Potamotrygon motoro in the Amazon River (Charvet-Almeida, 2004), Potamotrygon scobina in the mouth of the Amazon River (Almeida, 2003), and Potamotrygon orbignyi in the Paranã-Tocantins River (Rincon, 2006), and in the Xingu River (Charvet-Almeida, 2006). Despite their high degree of polychromatism, the taxonomic validity of these three species of Potamotrygon is uncontested by taxonomists specializing in chondrichthyans (Carvalho et al., 2003; Rosa and Carvalho, 2007).

To test the efficacy of DNA barcoding in delimiting potamotrygonid species, we generated the first comprehensive hypothesis of intra-familial phylogenetic relationships for the freshwater stingray family Potamotrygonidae and also evaluated the intraspecific genetic diversity of sampled species. We survey 10 out of the 18 valid species using a $522 \mathrm{bp}$ portion of the COI gene, to infer phylogenetic relationships within the family, to test alternate phylogenetic hypotheses, and to test the utility of DNA barcoding in this family.

\section{Material and Methods}

\section{Sampling of taxa}

We sampled six valid species and two non described species of the genus Potamotrygon with at least two individuals per species, for a total of 36 specimens (Table 1).

We analyzed the species Potamotrygon motoro $(\mathrm{n}=10)$, . orbignyi $(\mathrm{n}=6), P$. scobina $(\mathrm{n}=2), P$. leopoldi $(\mathrm{n}=2)$, P. falkneri $(\mathrm{n}=3)$, P. schroederi $(\mathrm{n}=4)$, Potamotrygon cf. motoro $(\mathrm{n}=4)$, and Potamotrygon sp. $1(\mathrm{n}=5)$. Potamotrygon sp.1 and Potamotrygon cf. motoro are endemic to the Amazonian Negro River and Tapajós River, respectively. Both species are well characterized morphologically and ecologically (Araújo, 1998; Carvalho, pers. com.), but have yet to be scientifically described. We also included sequences of $P$. henlei $(\mathrm{n}=1)$, and Plesiotrygon iwamae $(\mathrm{n}=1)$ from Marques (2000). As outgroup, we included the shark Heterodontus francisci (GenBank\# AJ310141), and the Myliobatiformes stingray species Hexatrygon bickelli (GenBank\# AY597334), and 
Table 1 - Analyzed species and localities of collection.

\begin{tabular}{llll}
\hline Species & $N$ & Site of collection & Reference \\
\hline Potamotrygon motoro & 1 & Aripuanã River, AM, Brazil $\left(06^{\circ} 00^{\prime} \mathrm{S}, 60^{\circ} 12^{\prime} \mathrm{W}\right)$ & Present study \\
& 2 & Janauacá Lake, AM, Brazil $\left(03^{\circ} 28^{\prime} \mathrm{S}, 60^{\circ} 17^{\prime} \mathrm{W}\right)$ & \\
& 1 & Parguaza River, AM, Venezuela $\left(06^{\circ} 24^{\prime} \mathrm{N}, 67^{\circ} 10^{\prime} \mathrm{W}\right)$ & \\
& 3 & Juruá River, AM, Brazil $\left(04^{\circ} 51^{\prime} \mathrm{S}, 66^{\circ} 51^{\prime} \mathrm{W}\right)$ & \\
& 1 & Jarauá River, AM, Brazil $\left(02^{\circ} 76^{\prime} \mathrm{S}, 64^{\circ} 88^{\prime} \mathrm{W}\right)$ & \\
Potamotrygon orbignyi & 1 & Itu River, AM, Brazil $\left(00^{\circ} 29^{\prime} \mathrm{S}, 63^{\circ} 15^{\prime} \mathrm{W}\right)$ & \\
& 2 & Demini River, AM, Brazil $\left(00^{\circ} 47^{\prime} \mathrm{S}, 62^{\circ} 56^{\prime} \mathrm{W}\right)$ & \\
Potamotrygon scobina & 4 & Aripuanã River, AM, Brazil $\left(06^{\circ} 07^{\prime} \mathrm{S}, 60^{\circ} 13^{\prime} \mathrm{W}\right)$ & Present study \\
& 1 & Pará River, PA, Brazil $\left(00^{\circ} 54^{\prime} \mathrm{S} 48^{\circ} 17^{\prime} \mathrm{W}\right)$ & Present study \\
Potamotrygon leopoldi & 1 & Aripuanã River, AM, Brazil $\left(06^{\circ} 07^{\prime} \mathrm{S}, 60^{\circ} 13^{\prime} \mathrm{W}\right)$ & \\
& 1 & Xingu River, PA, Brazil $\left(03^{\circ} 15^{\prime} \mathrm{S}, 52^{\circ} 04^{\prime} \mathrm{W}\right)$ & Present study \\
Potamotrygon falkneri & 1 & Xingu River, PA, Brazil $\left(03^{\circ} 34^{\prime} \mathrm{S}, 51^{\circ} 52^{\prime} \mathrm{W}\right)$ & \\
Potamotrygon schroederi & 3 & Paraná River, MS, Brazil $\left(20^{\circ} 45^{\prime} \mathrm{S}, 51^{\circ} 40^{\prime} \mathrm{W}\right)$ & Present study \\
& 1 & Caura River, BO, Venezuela $\left(06^{\circ} 50^{\prime} \mathrm{S}, 64^{\circ} 47^{\prime} \mathrm{W}\right)$ & Present study \\
Potamotrygon sp. 1 & 3 & Demini River, AM, Brazil $\left(00^{\circ} 46^{\prime} \mathrm{S}, 62^{\circ} 56^{\prime} \mathrm{W}\right)$ & \\
Potamotrygon cf. motoro & 2 & Aiuanã River, AM, Brazil $\left(00^{\circ} 52^{\prime} \mathrm{S}, 65^{\circ} 15^{\prime} \mathrm{W}\right)$ & Present study \\
Potamotrygon henlei & 3 & Itu River, AM, Brazil $\left(00^{\circ} 27^{\prime} \mathrm{S}, 63^{\circ} 37^{\prime} \mathrm{W}\right)$ & \\
Plesiotrygon iwamae & 4 & Tapajós River, PA, Brazil $\left(04^{\circ} 33^{\prime} \mathrm{S}, 56^{\circ} 15^{\prime} \mathrm{W}\right)$ & Present study \\
Himantura pacifica & 1 & Tocantins River & Marques (2000) \\
Hexatrygon bickelli & 1 & Solimões River & Marques (2000) \\
Heterodontus francisci & 1 & Panama & Marques (2000) \\
\hline Total & 1 & & GenBank: AY597334 \\
\hline
\end{tabular}

Himantura pacifica. The genus Himantura is considered the most likely sister taxon of Potamotrygonidae (Lovejoy, 1996; McEachran et al., 1996; Lovejoy et al., 1998; Dunn et al., 2003).

\section{DNA extraction, amplification and sequencing}

Total genomic DNA was extracted from muscle tissues preserved in alcohol by the standard protocol of Sambrook et al. (1989). We amplified the mitochondrial COI gene by the polymerase chain reaction (PCR) with the primers COIf 5'-ctgcaggaggagaycc-3' (forward) and COIa 5'-agtataagcgtctgggtagtc-3' (reverse), described by Palumbi and Benzie (1991). The PCR reactions were performed in $25 \mu \mathrm{L}$ reaction volume, containing $2.5 \mu \mathrm{L}$ of dNTPs $(2.5 \mathrm{mM}) ; 2.5 \mu \mathrm{L}$ of $10 \mathrm{X}$ buffer $(100 \mathrm{mM}$ Tris- $\mathrm{HCl}$, $500 \mathrm{mM} \mathrm{KCl}) ; 2 \mu \mathrm{L}$ from each primer $(2 \mu \mathrm{M}), 3 \mu \mathrm{L}$ of $\mathrm{MgCl}_{2}(25 \mathrm{mM}) ; 1 \mu \mathrm{L}$ of DNA (ca. $10 \mathrm{ng}$ ) e $1 \mathrm{U}$ of Taq DNA polymerase. The amplification cycles were carried out as follows: 35 cycles of denaturing at $92{ }^{\circ} \mathrm{C}$ for $1 \mathrm{~min}$; annealing at $52{ }^{\circ} \mathrm{C}$ for $35 \mathrm{~s}$; and extension at $72^{\circ} \mathrm{C}$ for $90 \mathrm{~s}$. A final extension was carried out at $72{ }^{\circ} \mathrm{C}$ for $5 \mathrm{~min}$. PCR products were visualized on $1 \%$ agarose gel. PCR products were then purified with the GFX PCR DNA Kit (GE Healthcare), and eluted in $20 \mu \mathrm{L}$ of elution buffer. Amplification primers were used as cycle sequencing primers, and cycle se- quencing reactions were carried out at $52{ }^{\circ} \mathrm{C}$ following the protocol recommended by the manufacturer of the kit $E T$ Terminator Cycle Sequencing Kit (GE Healthcare). Cycle sequencing reactions were carried out in a final volume of $10 \mu \mathrm{L}$ and contained $4 \mu \mathrm{L}$ of DNA, $2 \mu \mathrm{L}$ of $0.2 \mu \mathrm{M}$ primer, $2 \mu \mathrm{L}$ of buffer supplied in the $E T$ kit, and $2 \mu \mathrm{L}$ of $E T$ mix. Amplified products were precipitated using standard ammonium acetate/ethanol precipitation. Cycle sequencing products were resuspended in Hi-Di Formamide, and resolved on the MegaBACE 1000 (GE Healthcare) automatic sequencer.

\section{Alignment}

Sequences were aligned in ClustalW (Thompson et al., 1996) using default setting and edit by eye. ClustalW is implemented in the program BioEdit (Hall, 1999). Variable sites were checked in MEGA 3.0 (Kumar et al., 2004), and the complete alignment was translated into putative amino acids. The $522 \mathrm{bp}$ alignment did not show insertions or deletions, and conceptual translation did not reveal any unexpected stop codons.

\section{Phylogenetic analyses and hypotheses testing}

Phylogenetic analyses under neighbor-joining (NJ), Maximum-likelihood (ML), and Bayesian-inference (BI) optimality criteria were performed using PAUP* $4.0 \mathrm{~b} 10$ 
(Swofford, 2002). The NJ methodology is the standard method of phylogenetic inference in DNA barcoding studies (Hebert et al., 2003); its use in DNA barcoding studies is in part due to its strong track record in being able to rapidly analyze large species assemblages (Kumar and Gadagkar, 2000). The chosen molecular substitution model was the computationally simple Kimura-two-parameter (K2P) (Kimura, 1980) which is the standard model of molecular evolution used in DNA barcoding studies (Hebert et al., 2003). Robustness of the NJ topology was assessed using 2,000 bootstrap replicates.

We used the software Modeltest 3.7 (Posada and Crandall, 1998) to determine the best suited model of sequence evolution and the accompanying evolutionary parameter values for the data. The General Time Reversible (GTR) model of molecular evolution (Rodríguez et al., 1990), with rate homogeneity and a portion of sites treated as invariable, was determined to be the most likely model of sequence evolution. The GTR + inv model of sequence evolution was implemented in ML and BI analyses. Maximum-likelihood topology was also estimated in PAUP* $4.0 \mathrm{~b} 10$ (Swofford, 2002) with 25 heuristic searches using random addition of sequences, and implementing the tree bisection and reconnection (TBR) algorithm. Statistical robustness of the ML topology was accessed using 200 bootstrap replicates.

Bayesian-inference analysis was performed in the program MrBayes 3.01 (Ronquist and Huelsenbeck, 2003). The data were partitioned into three categories representing first, second, and third positions of the COI gene, each following the GTR + inv model of sequence evolution. We ran 2,000,000 generations using default long and short chain and heating parameters, sampling trees, and branch-length every 100 generations. Log likelihoods stabilized within the first $10 \%$ of the run, and therefore we discarded these initial 200,000 trees as burnin steps in the computation of a $50 \%$ majority rule consensus tree.

Pair-wise distances under Kimura-two-parameter (K2P), and maximum likelihood GTR + inv models of molecular evolution were generated in PAUP* $4.0 \mathrm{~b} 10$ (Swofford, 2002).

Alternate phylogenetic hypotheses were tested within the ML and NJ frameworks. Four hypotheses were tested: monophyly of $P$. motoro, monophyly of $P$. orbignyi, monophyly of $P$. scobina, and the reciprocal monophyly of the three species. We found the most likely or the best NJ trees that satisfied these constrains, and compared them against the most likely and best $\mathrm{NJ}$ topologies using the Kishino-Hasegawa (K-H) test (Kishino and Hasegawa, 1989), and Shimodaira-Hasegawa (S-H) tests (Shimodaira and Hasegawa, 1999). Assessment of significance was tested using the RELL bootstrap (Kishino et al., 1990). We also tested the hypothesis that our data follows a clock-like tempo of molecular evolution by enforcing the constraint of a clock-like mode of molecular evolution, and testing if this constraint resulted in a significantly less likely phylogenetic hypothesis using the likelihood-ratio test (Huelsenbeck and Rannala, 1997). To test if alleles of species were under natural selection, we used the McDonald-Kreitman test (McDonald and Kreitman, 1991) implemented in the program DnaSP 3.1 (Rozas et al., 2003).

\section{Results}

\section{Phylogenetic analyses}

The COI sequence alignment comprises 522 sites of which 180 were variable and 121 were parsimony informative (GenBank accession numbers EF532644-EF532683). Within Potamotrygonidae, the dataset contained 111 variable sites and 79 parsimony informative sites. All three methods of phylogenetic reconstruction indicated that the three most broadly distributed species in the Amazon basin, P. motoro, $P$. orbignyi, and $P$. scobina, are not reciprocally monophyletic (Figures 1-3). Monophyly of the other species including Potamotrygon sp. 1, and Potamotrygon cf. motoro, is statistically well supported in all analyses. The species $P$. motoro, $P$. orbignyi, $P$. scobina, P. leopoldi, $P$. falkneri, Potamotrygon cf. motoro, and $P$. henlei, hereafter called the rosette-spot clade, form a well defined and well supported clade; however, relationships among the species of the rosette-spot clade remain unresolved in all three methods of phylogenetic reconstruction (Figures 1-3).

The phylogenetic position of Plesiotrygon iwamae conflicts among NJ, ML, and BI analyses. In the NJ topology, Plesiotrygon iwamae appears as sister to all species of Potamotrygon (Figure 1). In the ML phylogeny, Plesiotrygon iwamae is sister to Potamotrygon schroederi, and Potamotrygon sp.1 appears as sister to the rest of the species of the family Potamotrygonidae (Figure 2). In the BI phylogeny, Plesiotrygon iwamae appears nested within Potamotrygon with $P$. schroederi as sister to other species in family (Figure 3). The internal tree branches within the Potamotrygonidae phylogeny are relatively short, especially within the rosette-spot clade.

Maximum parsimony analysis was not carried out since we have multiple individuals represented by the same haplotype which in turn resulted in a large number of equally parsimonious topologies. The consensus of these equally parsimonious topologies had the same phylogenetic pattern obtained in other analyses, but statistical tests could not be carried out efficiently.

Consistent with expectation, pair-wise genetic distances presented similar values for closely related species under both Kimura-two-parameter (K2P) and maximum likelihood GTR + inv models of molecular evolution. However, relatively smaller distances were found for distantly related species in K2P distance than in the GTR + inv model due to the inability of the K2P model to compensate for the accumulation of homoplaseous changes at deeper phylogenetic divergence (Tables 2 and 3). 


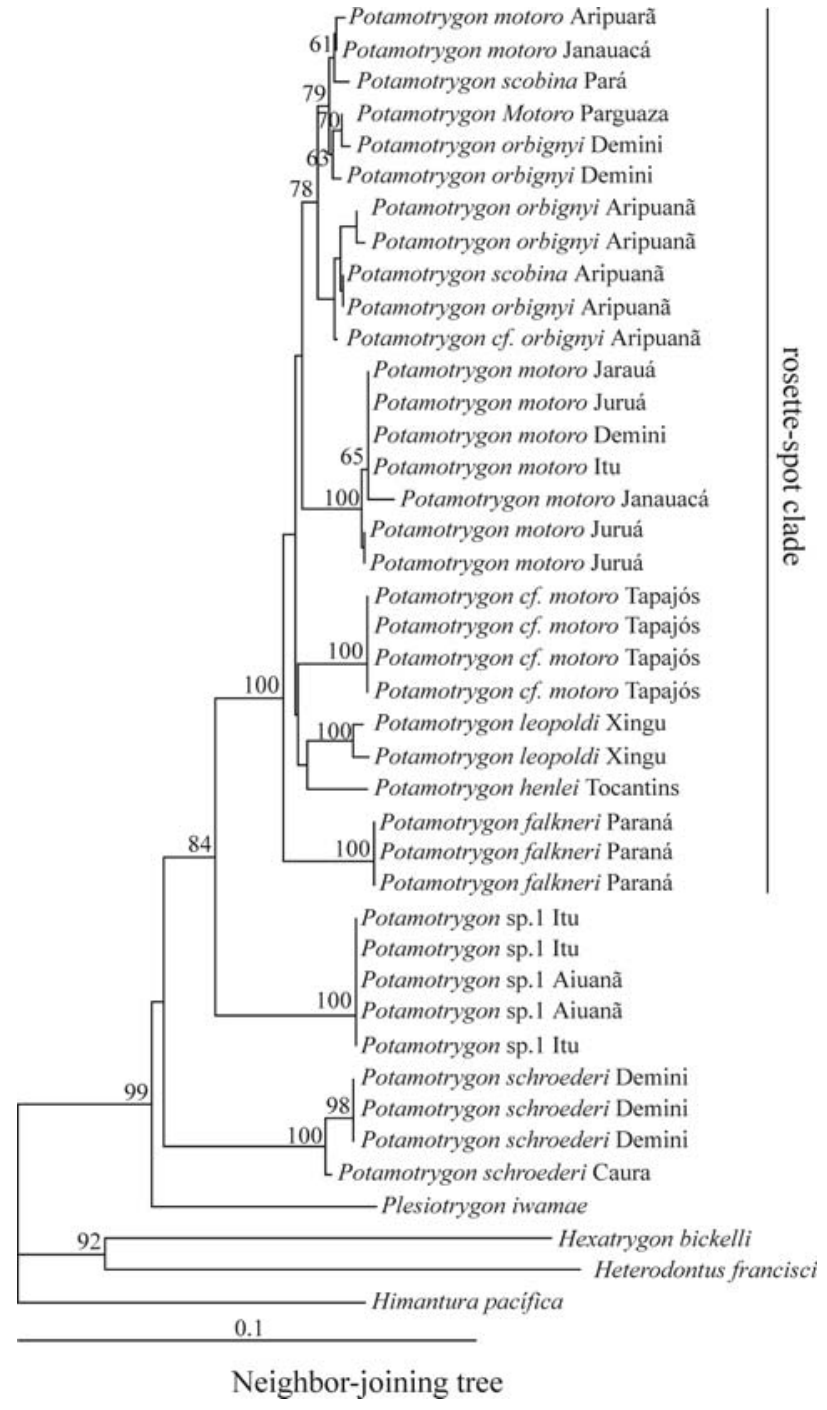

Figure 1 - Phylogenetic relationships of the potamotrygonids based on a Neighbor-Joining analyses of mitochondrial COI sequence data using K2P substitution model. Bootstrap values less than $50 \%$ were not shown. Plesiotrygon iwamae appears sister to all species of Potamotrygon. P. motoro, P. scobina, and P. orbignyi are non-monophyletic. The relationships among species of rosette-spot group are not well supported and branch lengths are short, evidence of a radiation.

Genetic distances among the species $P$. motoro, $P$. scobina, and $P$. orbignyi can not be considered true measures of divergence, since these species are not reciprocally monophyletic. Because of their lack of reciprocal monophyly, intraspecific genetic distances within these species show similar levels of divergence as among species measure of genetic distance (Table 2).

\section{Hypotheses testing}

Testing of alternate ML and NJ topological hypotheses under the Kishino-Hasegawa (1989) and Shimodaira-Hasegawa (1999) frameworks resulted in essentially the same conclusions (Tables 4 and 5). The monophyly of Potamotrygon motoro was not statistically rejected in the

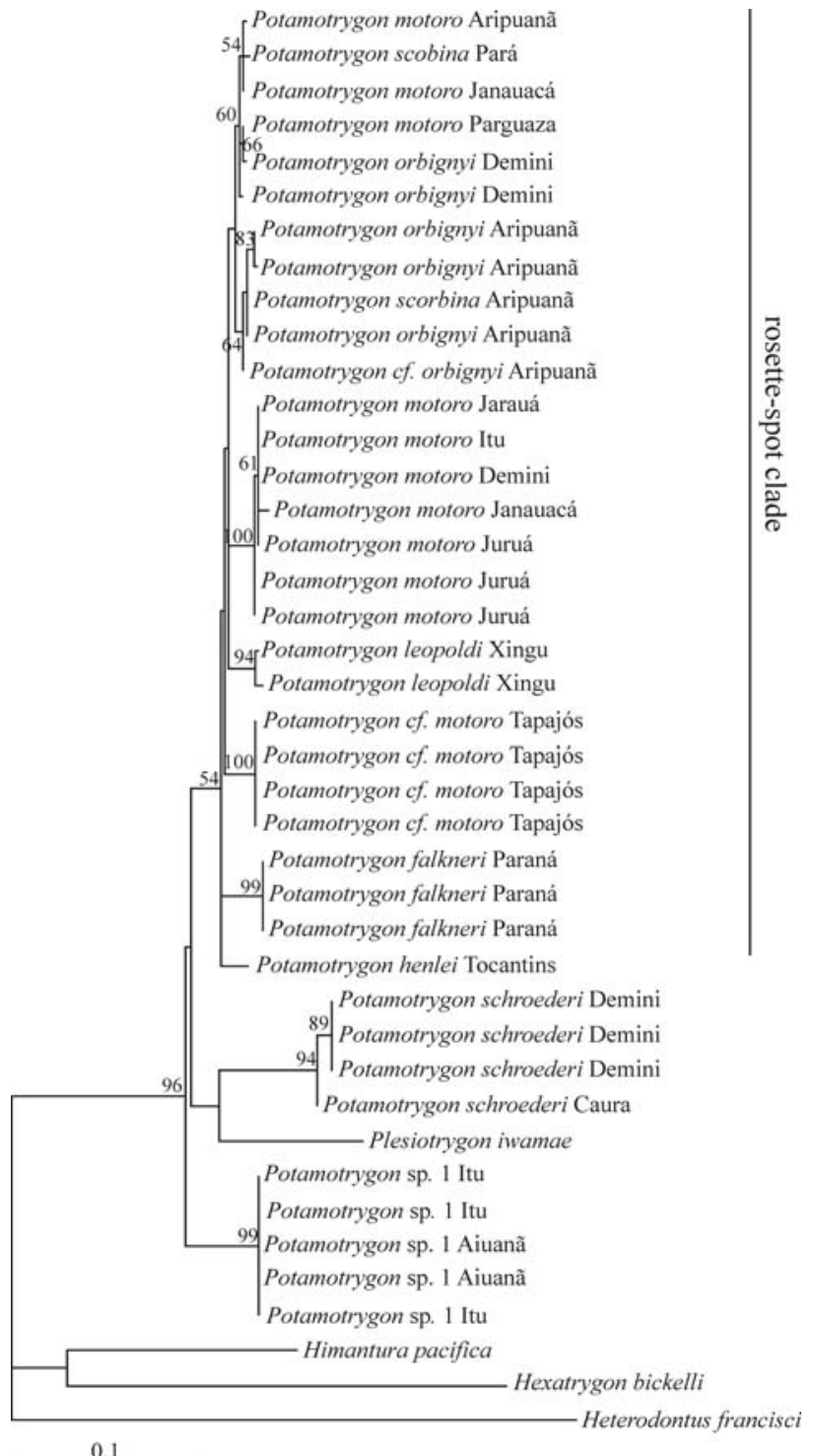

Maximum-likelihood analysis

Figure 2 - Phylogenetic relationships of the potamotrygonids based on a Maximum-Likelihood phylogenetic analyses of mitochondrial COI sequence data using GTR + inv substitution model. Plesiotrygon iwamae is sister to Potamotrygon schroederi and Potamotrygon sp.1 appears as the sister species of the family Potamotrygonidae. P. motoro, P. scobina, and $P$. orbignyi are non-monophyletic. The relationships among species of rosette-spot group are not well supported and branch lengths are short, evidence of a radiation.

ML topology and was only rejected by the K-H test in the NJ topology. Monophyly of $P$. orbignyi was rejected by both tests in the ML topology and the NJ topology. Likewise, monophyly of $P$. scobina was rejected in the ML topology by the K-H test, but not by the S-H test, and was rejected by both tests in the NJ topology. Enforcing the reciprocal monophyly of all three species resulted in significantly worse phylogenetic hypotheses under the ML criterion, as well as under the NJ phylogenetic estimate. Results of the McDonald-Kreitman test indicated that natural selec- 
tion is or was acting in $P$. orbignyi $(\mathrm{p}<0.05)$, however, overall sequence data evolve in a clock-like fashion (LTR test $\mathrm{p}>0.05)$.

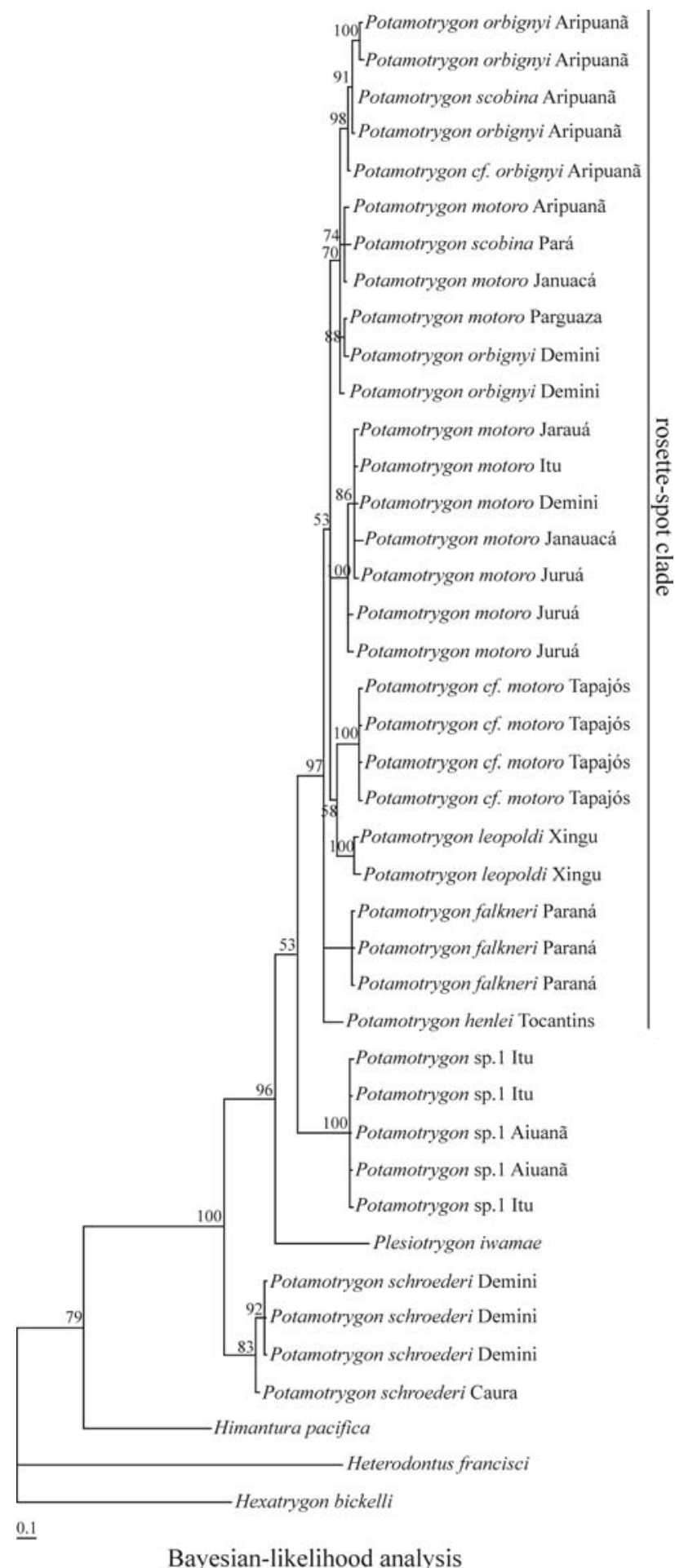

Figure 3 - Phylogenetic relationships of the potamotrygonids based on a Bayesian-inference phylogenetic analyses of mitochondrial COI sequence data using GTR + inv substitution model. Plesiotrygon iwamae appears nested within Potamotrygon with Potamotrygon schroederi as sister species of the family. P. motoro, P. scobina, and P. orbignyi are non-monophyletic. The relationships among species of rosette-spot group are not well supported and branch lengths are short, evidence of a radiation.

\section{Discussion}

Potamotrygonidae is the only family of the Class Chondrichthyes that is considered completely adapted to living in fresh water (Thorson et al., 1983). Initial phylogenetic studies of Rosa (1985), Lovejoy (1996), Lovejoy et al. (1998), and Marques (2000) aimed to test the monophyly of this family, to infer the phylogenetic relationships among its three described genera, and to establish its sister group. These studies supported the monophyly of the Potamotrygonidae and most of them concluded that colonization of fresh water in South America is the result of a single colonization event. The majority of authors also considered the marine genus Himantura to be the sister taxon of Potamotrygonidae. Relationships within the Potamotrygonidae were hypothesized as (Paratrygon (Plesiotrygon (Potamotrygon))), although Marques (2000) and Quijada (2003) found Plesiotrygon nested within Potamotrygon. The first attempt to define species relationships within the genus Potamotrygon was made by Marques (2000), although his study was based on only few specimens per species and species were not sampled throughout their geographical distribution. This sampling design assumes that species are monophyletic with respect to the alleles at the studied locus, and that they show no or only very limited intraspecific variation (Funk and Omland, 2003). In turn, this assumption requires that nominal study species represent genetically and reproductively independent lineages whose boundaries have been accurately identified by taxonomists and whose reconstructed gene trees are accurate approximations of organismal history, i.e. species trees (Funk and Omland, 2003). This scenario also does not accommodate species that are paraphyletic or polyphyletic, cases extensively reported in the literature (Funk and Omland, 2003, and references therein). Non-reciprocal monophyly of species can, for example, be caused by the retention of ancestral polymorphism or introgression following a hybridization event (Avise, 2000; Moritz and Cicero, 2004). In our phylogenetic analysis we sampled four species in at least two different localities, and majority of species are represented by at least four individuals. Even with this sampling scheme, we find extensive haplotype sharing, and lack of monophyly in three out of the eight investigated species with more than one specimen sampled.

\section{Potamotrygon motoro, Potamotrygon scobina, and Potamotrygon orbignyi}

We found that three of the four species with broadest distribution in the Amazon basin (the fourth species Paratrygon aiereba was not included in this study), species which also are highly polymorphic, were not reciprocally monophyletic, and extensively shared haplotypes among species. Haplotype sharing may indicate that $i$ ) taxonomic validity of these species should be reassessed; $i i$ ) lineages did not have enough time to reach reciprocally monophyly; iii) hybridization; or $i v$ ) combination of these factors (Moritz and Cicero, 2004). 


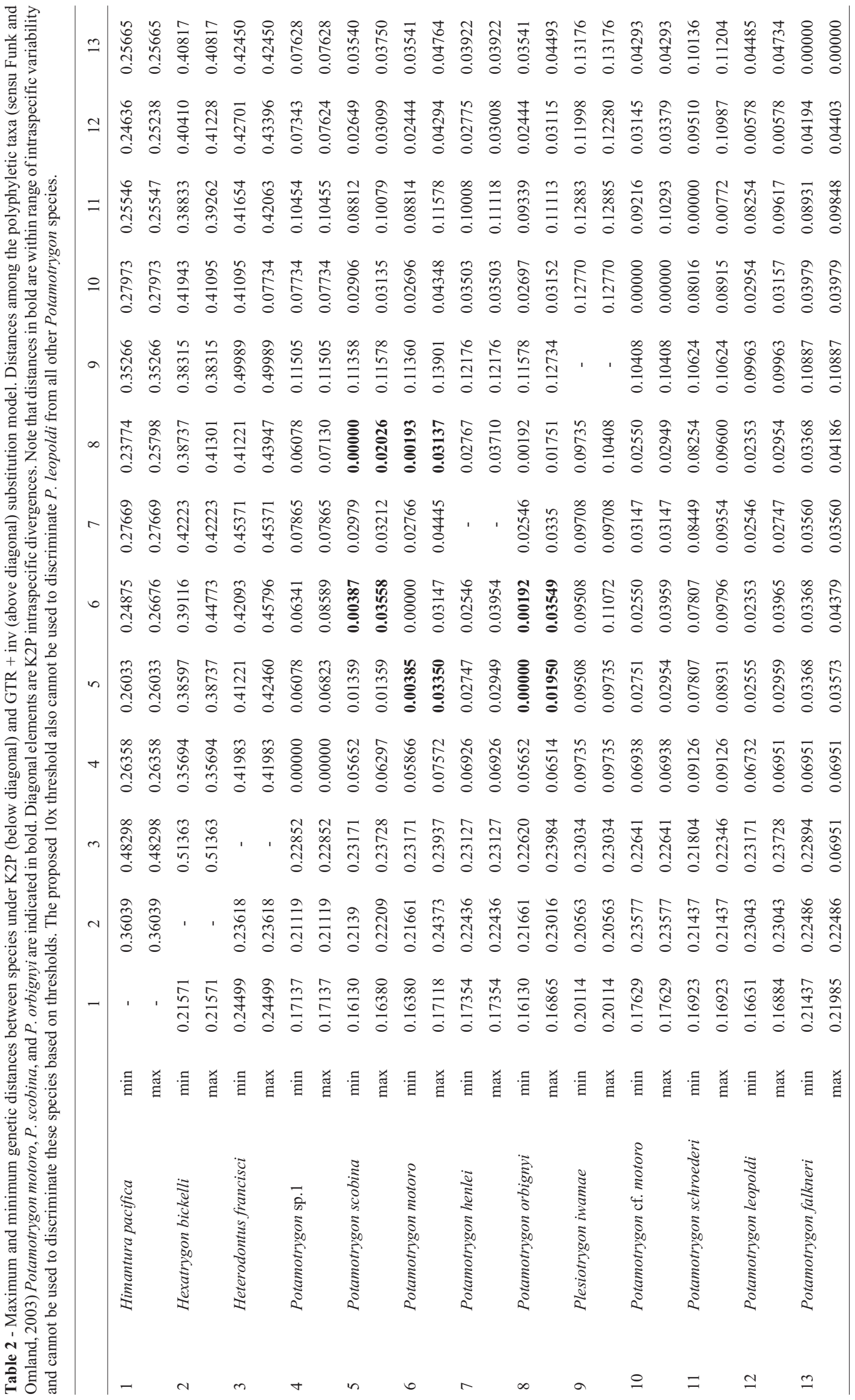


Table 3 - Distances among outgroup taxa and an average of Potamotrygonidae species under K2P and GTR + inv model of evolution.

\begin{tabular}{lcc}
\hline & K2P distance & ML distance \\
\hline Himantura x Potamotrygonidae & 0.17713 & 0.27001 \\
Hexatrygon x Potamotrygonidae & 0.22182 & 0.39907 \\
Heteredontus x Potamotrygonidae & 0.22241 & 0.43416 \\
\hline
\end{tabular}

The phylogenetic results are consistent with the possibility that these species can actually represent one highly polychromatic species with broad geographical distribution within the Amazon basin. There is overlap in some morphometric characters (Rosa, 1985), although this author mostly measured juveniles, and there is also a large amount of color and pattern variation within P. scobina from the Marajó Bay (Almeida, 2003), and P. orbignyi from the Tocantins River (Rincon, 2006). There also appears to be some overlap in color pattern among the species $P$. motoro, $P$. orbignyi, and P. scobina from various places in the Amazon basin (Araújo and Toffoli, unpublished data). For examples of color patterns see electronic appendix at http://www.evoamazon.net/publications. However, there are also several morphological as well as ecological characters that have been argued to separate these species. Differences between $P$. scobina and $P$. orbignyi include presence/absence of a labial furrow (Almeida, 2003), color of the ventral portion of tail, teeth cuspid, and dorsal color patterns (Rincon, 2006).

Another hypothesis is that P. motoro, P. orbignyi, and $P$. scobina are true evolutionary species, and $P$. motoro is the ancestor. Although non-monophyletic, very little haplotype sharing among geographic localities of $P$. scobina and
$P$. orbignyi occurs, and both species are phylogenetically nested within P. motoro. Potamotrygon scobina and $P$. orbignyi may be in the process of incipient speciation with not yet well defined species borders. The observed selection acting on $P$. orbignyi supports this scenario, as does a phylogeographic analysis (Toffoli, 2006), but additional data including ecological, behavioral, and populational studies are needed to test this hypothesis rigorously. The potential role of hybridization in the diversification of this group is unknown.

\section{Phylogenetic relationships within the rosette-spot clade - "The Radiation"}

Phylogenetic relationships among species of the rosette-spot clade are not resolved. With the exception of Potamotrygon motoro, P. orbignyi and P. scobina, the monophyly of all other species is well supported, but no statistical support exists for phylogenetic relationships among them. This pattern suggests that the rosette-spot clade underwent or is still in the process of phylogenetic radiation, resulting in a rapid increase in number of species (Schluter, 2000). A phylogenetic signature of this process is generally a polytomy, due to extremely short evolutionary periods that separate successive speciation events. This prevents the accumulation of synapomorphic characters at internode branches, leading to the failure of all phylogenetic methods to reconstruct a statistically supported bifurcating topology. Radiations are not rare or restricted in time or space, and usually fill a previously unoccupied niche. Some examples include the Cambrian radiation (Philippe et al., 1994; Bromham et al., 1998; Conway-Morris, 1999), Anolis lizards from the Caribbean (Jackman et al., 1999),

Table 4 - Results of ML constraint tests of monophyly of species Potamotrygon motoro, P. orbignyi, and P. scobina. * $\mathrm{p}<0.05$.

\begin{tabular}{lcccc}
\hline Topology type & & & KH-test & SH-test \\
& $-\ln \mathrm{L}$ & Diff $-\ln \mathrm{L}$ & $\mathrm{p}$ & \\
\hline Unconstrained topology & 2267.274 & (best) & & \\
Monophyly of P. motoro & 2287.596 & 20.322 & 0.057 & 0.078 \\
Monophyly of P. orbignyi & 2293.598 & 26.323 & $0.022^{*}$ & $0.017 *$ \\
Monophyly of P. scobina & 2287.120 & 19.846 & $0.037^{*}$ & 0.059 \\
Reciprocal monophyly of P. motoro, P. orbignyi, and P. scobina & 2318.833 & 51.559 & $0.003^{*}$ & $0.003^{*}$ \\
\hline
\end{tabular}

Table 5 - Results of NJ constraint tests of monophyly of species Potamotrygon motoro, P. orbignyi, and P. scobina. *p $<0.05$.

\begin{tabular}{lcccc}
\hline Topology type & & KH-test & SH-test \\
& $-\ln \mathrm{L}$ & Diff -ln L & $\mathrm{p}$ & \\
\hline Unconstrained topology & 2270.696 & (best) & & \\
Monophyly of P. motoro & 2289.381 & 18.685 & $0.034^{*}$ & 0.123 \\
Monophyly of P. orbignyi & 2297.192 & 26.496 & $0.010^{*}$ & $0.011^{*}$ \\
Monophyly of P. scobina & 2293.614 & 22.918 & $0.013^{*}$ & $0.037^{*}$ \\
Reciprocal monophyly of P. motoro, P. orbignyi, and P. scobina & 2322.812 & 52.116 & $0.009^{*}$ & $0.009^{*}$ \\
\hline
\end{tabular}


the Hawaiian silversword alliance (Baldwin and Sanderson, 1998), cichlid fishes of the east African lakes (Avise, 1990; Turner et al., 2001), and sciaenid fishes of the western Atlantic (Vinson et al., 2004), among others.

\section{Rooting the Potamotrygonidae}

In the NJ topology, Plesiotrygon iwamae appears sister to all species of Potamotrygon (Figure 1), in the ML phylogeny, Plesiotrygon iwamae is sister to Potamotrygon schroederi (Figure 2), and in the BI phylogeny, Plesiotrygon iwamae appears nested with Potamotrygon (Figure 3). The phylogenetic relationship of Plesiotrygon iwamae in the ML topology is not statistically supported by a high bootstrap value. Despite these conflicts, the unrooted ingroup topology among Plesiotrygon iwamae, Potamotrygon schroederi, Potamotrygon sp.1, and the rosette-spot clade of Potamotrygon remains the same in all three methods of phylogenetic inference (Figure 4). Correct placement of the root is especially difficult in phylogenies with relatively short internal branches rooted by a distantly related or highly divergent outgroup. Classic example involves the placement of the root of birds whose closest relatives are the distantly related crocodilians, and vice versa (Mindell et al., 1999; García-Moreno and Mindell, 2000).

a) Neighbor-Joining root

rosette-spot group Potamotrygon schroederi

b)

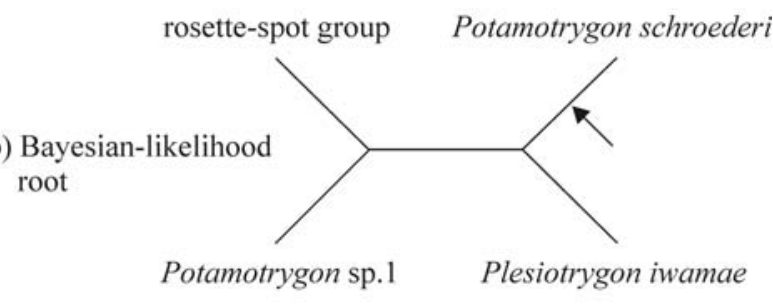

c) Maximum-likelihood root Potamotrygon sp.1

Plesiotrygon iwamae

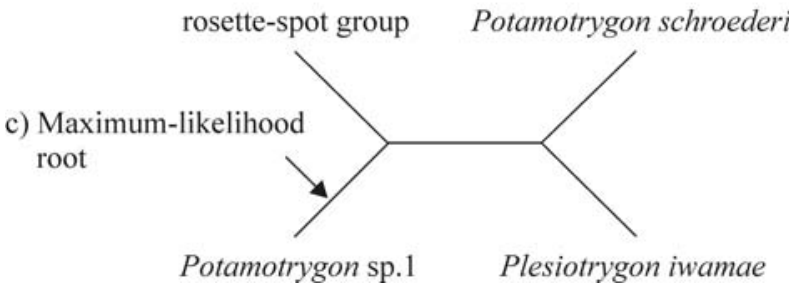

Figure 4 - Schematic representation of the ingroup topology which is recovered by all three methods of phylogenetic inference. Arrows represent rooting points of the different analyses: a) Neighbor-joining root; b) Bayesian-inference root; c) Maximum-likelihood root. See text for discussion.
The average maximum likelihood within Potamotrygonidae distance is $5.9 \%$, while the average maximum likelihood distance observed between Potamotrygonidae and the Himantura sister group is $27.0 \%$, and higher to other cartilaginous outgroup species (Table 3). Therefore, it is not entirely surprising that the root of the Potamotrygonidae is difficult to place. However, we suspect that Plesiotrygon iwamae is phylogenetically nested within Potamotrygon, as suggested by the ML and BI topologies (Figures 2 and 3). This supposition is derived from the use of a more complex and more appropriate model of molecular evolution in the ML and BI analyses, and the consistently better performance of likelihood-based methods of phylogenetic inference when proper models of molecular evolution are used (Huelsenbeck and Hillis, 1993; Hillis et al., 1994). Eliminating third codon positions or translating the sequence data into putative amino acids, and analyzing these datasets using NJ also places Plesiotrygon iwamae within the genus Potamotrygon (results not shown). Furthermore, the inference drawn from the ML and BI topology is supported by Marques (2000) and Quijada (2003) who also hypothesize the paraphyly of Potamotrygon and the nested position of Plesiotrygon with Potamotrygon.

\section{DNA barcoding}

Studies supporting DNA barcoding often do not compare sister species which are the natural candidates to share haplotypes (Moritz and Cicero, 2004). Assuming that Potamotrygon motoro, P. scobina, and P. orbignyi are valid species in the sense of being a natural kind, our results showed that the use of DNA sequences to assign unknown specimens to any of these three species would invariably fail. Correct assignment would only be possible with the addition of other data types such as morphological, ecologi$\mathrm{cal}$, and behavioral characters, or even haplotype frequency data if non-random distribution of haplotypes across geography existed. Methodologies such as DNA barcoding which rely solely on one data type and one criterion will inevitably have higher failure rates than those incorporating diverse sources of information. Substituting one character-type philosophical system (e.g., based on meristic characters) of taxonomy for another one character-type system (e.g., based on COI DNA barcoding) will not solve existing taxonomic problems. One system may clarify some taxonomic questions, but it will also obscure other questions. Thus, unless a holistic approach to taxonomy and systematics is used we will inevitably fail to understand important aspects of biological diversity.

With the above caveat in mind, and assuming our sampling is representative of the genetic diversity present in the remaining analyzed Potamotrygon species, the remaining species surveyed in this study form monophyletic and well supported groups separated by reasonably large genetic distances. This pattern would allow the use of the COI phylogeny to assign unknown specimens to their cor- 
rect species, as proposed by the Barcoding Consortium. However, this assignment is critically dependent on sufficiently dense genetic sampling of the group studied, i.e. it requires populational rather than typological sampling. The case of specimens from the Caura River, Venezuela, and specimens from Negro River, Brazil, is an illustrative example. As recognized morphologically, P. schroederi occurs both in the Negro and Orinoco River basins; the type specimen was from the Orinoco, but after being lost, a neotype was designated from the Negro River (Carvalho, 2001).

Our analyses indicate that the Venezuelan Caura River specimen is sister to the Negro River specimens, and separated by $0.8 \%$ sequence divergence. The genetic divergence of $0.8 \%$ is relatively low compared to the average $2.5 \%$ among rosette-spot clade divergence, and would indicate, based on barcoding assumptions, that fishes from the Caura and the Negro Rivers represent a single species. This barcoding-based inference is predicated on the assumption that the clades from which these individuals were sampled are sister, an assumption which critically hinges on taxonomic sampling. On the other hand, the color pattern of the Orinoco basin P. schroederi is quite different when compared to animals from Negro River. The Negro/Orinoco watershed divide represents a major barrier to gene flow for a number of species, with numerous instances of sister species occurring on either side of the divide (Reis et al., 2003), and therefore it is possible that $P$. schroederi from the Negro and Caura Rivers represent different species. We, therefore, can neither accept nor reject that $P$. schroederi occurring on either side of the Negro/Orinoco watershed divide represents more than one species. These results pose serious questions about the exclusive reliance on the DNA barcoding methodology in species identification, at least for the freshwater stingrays of the family Potamotrygonidae.

Assuming that species are well characterized, are monophyletic, and that intraspecific divergence is much smaller than interspecific divergence, criteria that can only be verified through populational rather than the currently prevalent typological sampling and analyses, DNA barcoding should be powerful in assigning unknown samples to species. However, DNA barcoding is not powerful in discovering new species using the proposed threshold methods as advocated by Hebert et al. (2003). For example, in a comprehensive study of the adoption of threshold values for three thoroughly sampled groups of invertebrates, Meyer and Paulay (2005) found a significant overlap of intraspecific genetic variability and interspecific distance, providing strong evidence against the adoption of thresholds. Furthermore, the use of thresholds implicitly assumes that molecular sequences evolve in a clock-like manner. While we cannot reject a clock-like mode of molecular evolution in the potamotrygonid COI dataset, a clock-like mode of molecular evolution is rare in all groups of organ- ism (for a review see $\mathrm{Li}, 1997$ ) which resulted in the development of multiple algorithms specifically taking this fact into account in the calculation of divergence times (Sanderson, 1997, 2002; Thorne and Kishino, 2002).

DNA barcodes have been proposed as a fast, efficient, and inexpensive way to catalogue all biodiversity (Hebert et al., 2003). However, most studies that advocate usefulness of barcoding actually test its assumptions in already predefined taxonomic groups based on previous works, whereas true barcoding consists of broad, essentially blind and random surveys of communities, with little or no background taxonomic information (Rubinoff, 2006a). The study of Hajibabaei et al. (2006) is one of the most striking positive results of barcoding, identifying $98 \%$ of previously well characterized species of tropical Lepidoptera. However, Funk and Omland (2003) found species level paraphyly and polyphyly in $23 \%$ of 2,319 vertebrate species whose mitochondrial genomes were surveyed. The Lepidoptera results (Hajibabaei et al., 2006) should be seen as an exception rather than norm. The study does not report the intraspecific sampling scheme used.

The more geographically widespread a species is, the higher is the probability of finding elevated levels of intraspecific variability if the species is sampled across its distributional range. Consequently, such a study would have a higher probability of finding overlaps between genetic distance among closely related species and variability within a species, making even more questionable the establishment of thresholds, as well as increasing the likelihood of observing paraphyly and polyphyly. If, however, all specimens of a particular species were sampled from the same locality, one is likely to observe much less intraspecific variability than if sampling was done across a distributional range of the species. This consequently would lead to a reduction in the variation within species, and to a reduction in the number of observed cases of paraphyly and polyphyly. The degree of difference between intraspecific and interspecific divergence would also be overestimated.

The fundamental problem with using thresholds lies in the fact that species are a natural kind that embody an evolutionary process. Species are subject to demographic and selective processes that will act to increase or decrease genetic diversity and coalescent depth of individual species (e.g., Avise, 2000; Hey, 2001; Coyne and Orr, 2004). Species may not be morphologically distinct from other species, yet be genetically distinct (e.g., Hrbek et al., 2006), and conversely species may be morphologically distinct without being genetically distinct (e.g., Verheyen et al., 2003; Duda Jr. and Rolán, 2005). Species are real evolutionary groups and not categories which are created as a direct function of perceived distinction (Hey, 2001). Species are not categories defined by criteria, such as amount of sequence divergence. Therefore, the use of thresholds in "discovering" new species is overly simplistic, misleading, and invalid. 
Freshwater stingrays are a taxonomic group similar to several other tropical biota in the sense that much taxonomy is yet to be done and therefore a good exercise for testing usefulness of barcoding in discovery life on Earth. We found that four out of 10 species surveyed (40\%) could not be discriminated by barcoding criteria (we observed sharing of haplotypes among Potamotrygon motoro, $P$. orbignyi, and $P$. scobina, and small sequence divergence between $P$. aff. schroederi from Venezuela and $P$. schroederi from Negro River). DeSalle (2006) advocates that DNA barcoding should focus mainly on the identification of specimens rather than the discovery of new species, which should be essentially the domain of taxonomy. However, this radically changes the main goal of barcoding, which is identification of life on Earth in a cost-effective fashion. This mission makes it obligatory to deal with taxonomic groups in which previous taxonomic efforts are virtually nonexistent. The results of the current and other studies pose serious doubts of the appeal of designating billions of dollars to the barcoding enterprise (Cameron et al., 2006; Rubinoff, 2006a,b). So should one trust and rely on barcoding? By any standard, 23\% (Funk and Omland, 2003 ) or even higher ( $40 \%$ - present study) failure rates to identify taxonomically valid species are not acceptable, and the political, economical, and environmental consequences of using DNA barcoding as currently proposed can be enormous.

\section{Acknowledgments}

This research was supported in part by a research grant from the Fundação de Amparo à Pesquisa do Estado do Amazonas (FAPEAM), and International Foundation for Science (IFS) to IPF, and the BECA program to DT. Permission to conduct fieldwork and to collect tissue samples was granted by IBAMA (License n. 05/2005 and 098/2006-DIFAP), and to conduct genetic assessment by CGEN/IBAMA (Deliberation n. 025/2005). We thank Piagaçu-Purus RDS and PROBIO personnel especially Rafael Bernhard, Stuart Willis, and local fishermen for helping us to obtain tissue samples, and Aureo Banhos dos Santos and Adam Souza de Alencar Leão for help in the laboratory. This article forms a portion of DT's Masters Thesis at the Genetics, Conservation and Evolutionary Biology program of INPA/UFAM; DT acknowledges CAPES for financial support during his Masters tenure.

\section{References}

Achenbach GM and Achenbach SVM (1976) Notas acerca de algunas especies de raya fluvial (Batoidei, Potamotrygonidae), que frecuentam el sistema hidrografico del Rio Parana medioen el departamento La Capital. Com Mus Prov Cien Nat "Florentino Ameghino" 8:3-34.

Almeida MP (2003) Pesca, policromatismo e aspectos sistemáticos de Potamotrygon scobina, Garman 1913 (Chondrichthyes, Potamotrygonidae) da região da Ilha de Colares da
IIha de Marajó, Pará. M.Sc. Thesis, Universidade Federal do Pará and Museu Paraense Emílio Goeldi, Belém.

Araújo MLG (1998) Biologia reprodutiva e pesca de Potamotrygon sp. C (Chondrichthyes, Potamotrygonidae), no médio rio Negro, Amazonas. M.Sc. Thesis, Universidade Federal do Amazonas and Instituto Nacional de Pesquisas da Amazônia, Manaus.

Avise JC (1990) Flocks of African fishes. Nature 347:512-513.

Avise JC (2000) Phylogeography: The History and Formation of Species. Harvard University Press, Cambridge, 384 pp.

Baldwin BG and Sanderson MJ (1998) Age and rate of diversification of the Hawaiian silversword alliance (Compositae). Proc Natl Acad Sci USA 95:9402-9406.

Bromham L, Rambaut A, Fortey R, Cooper A and Penny D (1998) Testing the Cambrian explosion hypothesis by using a molecular dating technique. Proc Natl Acad Sci USA 95:12386-12389.

Cameron S, Rubinoff D and Will K (2006) Who will actually use DNA barcoding and what will it cost? Syst Biol 55:844-847.

Carvalho MR (2001) Review of: Freshwater Stingrays from South America. Copeia 4:1167-1169.

Carvalho MR, Lovejoy NR and Rosa RS (2003) Family Potamotrygonidae (river stingrays). In: Reis RE, Kullander SO and Ferraris CJ (eds) Check List of the Freshwater Fishes of South and Central America. EDIPUCRS, Porto Alegre, pp 22-28.

Castex MN (1964) Estado actual de los estudios sobre la raya fluvial neotropical. In: Cincuentenario del Museo Provincial de Ciencias Naturales "Florentino Ameghino". Museo Provincial de Ciencias Naturales "Florentino Ameghino", Santa Fé, pp 9-49.

Castex MN, Maciel I and Achenbach GM (1963) Acerca de la raya fluvial $P$. labradori. Neotropica 9:117-121.

Charvet-Almeida P (2001) Ocorrência, biologia e uso das raias de água doce na baía de Marajó (Pará, Brasil), com ênfase na biologia de Plesiotrygon iwamae (Chondrichthyes, Potamotrygonidae). MSc Thesis, Universidade Federal do Pará and Museu Paraense Emílio Goeldi, Belém.

Charvet-Almeida P (2006) Historia natural e conservação das raias de água doce (Chondrichthyes, Potamotrygonidae) no médio Rio Xingu, área de influência do projeto hidrelétrico de Belo Monte (Pará, Brasil). PhD Thesis, Universidade Federal da Paraíba.

Charvet-Almeida P (2004) Sub-Estudo Elasmobrânquios. Relatório Técnico agosto de 2004. Estudo Estratégico n. 8, Bases Científicas para a Conservação da Várzea: Identificação e Caracterização de Zonas Biogeográficas. Pro Várzea/ IBAMA, Manaus.

Conway-Morris S (1999) The Crucible of Creation: The Burgess Shale and the Rise of Animals. Oxford University Press, New York, 276 pp.

Coyne JA and Orr HA (2004) Speciation. Sinauer Associates, Inc., Sunderland, $545 \mathrm{pp}$.

DeSalle R (2006) Species discovery $v s$. species identification in DNA barcoding efforts: Response to Rubinoff. Conserv Biol 20:1545-1547.

Duda Jr TF and Rolán E (2005) Explosive radiation of Cape Verde Conus, a marine species flock. Mol Ecol 14:267-272.

Dunn KA, McEachran JD and Honeycutt RL (2003) Molecular phylogenetics of myliobatiform fishes (Chondrichthyes, Myliobatiformes), with comments on the effects of missing 
data on parsimony and likelihood. Mol Phylogenet Evol 27:259-270.

Funk DJ and Omland KE (2003) Species-level paraphyly and polyphyly: Frequency, causes, and consequences, with insights from animal mitochondrial DNA. Annu Rev Ecol Syst34:397-423.

García-Moreno J and Mindell DP (2000) Rooting a phylogeny with homologous genes on opposite sex chromosomes (gametologs): A case study using avian CHD. Mol Biol Evol 17:1826-1832.

Hajibabaei M, Janzen DH, Burns JM, Hallwachs W and Hebert PDN (2006) DNA barcodes distinguish species of tropical Lepidoptera. Proc Natl Acad Sci USA 103:968-971.

Hall T (1999) BioEdit: A user-friendly biological sequence alignment editor and analysis program for Windows 95/98/NT. Nucleic Acids Symp Ser 41:95-98.

Hebert PDN, Cywinska A, Ball SL and deWaard JR (2003) Biological identifications through DNA barcodes. Proc R Soc London B 270:313-321.

Hebert PDN, Stoeckle MY, Zemlak TS and Francis CM (2004) Identification of birds through DNA barcodes. PLoS Biol 2:1657-1663.

Hey J (2001) Genes, Categories and Species: The Evolutionary and Cognitive Causes of the Species Problem. Oxford University Press, New York, 217 pp.

Hillis DM, Huselsenbeck JP and Cunningham CW (1994) Application and accuracy of molecular phylogenies. Science 264:671-677.

Hrbek T, Keivany Y and Coad BW (2006) New species of Aphanius (Teleostei, Cyprinodontidae) from Isfahan province of Iran and a reanalysis of other Iranian species. Copeia 2006:244-255.

Huelsenbeck JP and Hillis DM (1993) Success of phylogenetic methods in the four-taxon case. Syst Biol 42:247-264.

Huelsenbeck JP and Rannala B (1997) Phylogenetic methods come of age: Testing hypotheses in an evolutionary context. Science 276:227-232.

Jackman TR, Larson A, de Queiroz K and Losos JB (1999) Phylogenetic relationships and tempo of early diversification in Anolis lizards. Syst Biol 48:254-285.

Johnson NK and Cicero C (2004) New mitochondrial DNA data affirm the importance of Pleistocene speciation in North American birds. Evolution 58:1122-1130.

Kimura M (1980) A simple method for estimating evolutionary rates of base substitutions through comparative studies of nucleotide sequences. J Mol Evol 16:111-120.

Kishino H and Hasegawa M (1989) Evaluation of the maximum likelihood estimate of the evolutionary tree topologies from DNA sequence data, and the branching order in Hominoidea. J Mol Evol 29:170-179.

Kishino H, Miyata T and Hasegawa M (1990) Maximum likelihood inference of protein phylogeny and the origin of chloroplasts. J Mol Evol 30:151-160.

Kumar S and Gadagkar SR (2000) Efficiency of the neighbourjoining method in reconstructing deep and shallow evolutionary relationships in large phylogenies. J Mol Evol 51:544-553.

Kumar S, Tamura K and Nei M (2004) MEGA3: Integrated software for molecular evolutionary genetics analysis and sequence alignment. Briefings Bioinfor 5:150-163.
Li W-H (1997) Molecular Evolution. Sinauer Associates, Sunderland, $487 \mathrm{pp}$.

Lovejoy NR (1996) Systematics of myliobatoid elasmobranchs: With emphasis on the phylogeny and historical biogeography of neotropical freshwater stingrays (Potamotrygonidae, Rajiformes). Zool J Linn Soc 117:207-257.

Lovejoy NR, Bermingham E and Martin AP (1998) Marine incursion into South America. Nature 396:421-422.

Marques FPL (2000) Evolution of neotropical freshwater stingrays and their parasites: Taking into account space and time. Ph.D. Thesis, University of Toronto, Toronto.

McDonald JH and Kreitman M (1991) Adaptive protein evolution at Adh locus in Drosophila. Nature 351:652-654.

McEachran JD, Dunn KA and Miyake T (1996) Interrelationships within the batoid fishes (Chondrichthyes, Batoidea). In: Stiassny MLJ, Parenti LR and Johnson GD (eds) Interrelationship of Fishes. Academic Press, New York, pp 63-84.

Meyer CP and Paulay G (2005) DNA barcoding: Error rates based on comprehensive sampling. PLoS Biol 3:2229-2238.

Mindell DP, Sorenson MD, Dimcheff DE, Hasegawa M, Ast JC and Yuri T (1999) Interordinal relationships of birds and other reptiles based on whole mitochondrial genomes. Syst Biol 48:138-152.

Moritz C and Cicero C (2004) DNA barcoding: Promises and pitfalls. PLoS Biol 2:1529-1534.

Quijada CCD (2003) Relações filogenéticas intergenéricas de raias neotropicais de água doce (Chondricthyies, Potamotrigonidae). M.Sc. Thesis, Universidade Estadual da Paraíba, João Pessoa.

Palumbi SR and Benzie J (1991) Large mitochondrial DNA differences between morphologically similar Penaeid shrimp. Mol Mar Biol Biotech 1:27-34.

Philippe H, Chenuil A and Adoutte A (1994) Can the Cambrian explosion be inferred through molecular phylogeny? Development 1994(suppl):15-25.

Posada D and Crandall KA (1998) MODELTEST: Testing the model of DNA substitution. Bioinformatics 14:817-818.

Reis RE, Kullander SO and Ferraris CJ (2003) Check List of the Freshwater Fishes of South and Central America. EDIPUCRS, Porto Alegre, $734 \mathrm{pp}$.

Rincon GF (2006) Aspectos taxonômicos, alimentação e reprodução da raia de água doce Potamotrygon orbignyi (Castelnau) (Elasmobranchii, Potamotrygonidae) no rio Paranã-Tocantins. Ph.D. Thesis, Universidade Estadual Paulista "Julio de Mesquita Filho", Rio Claro.

Rodríguez FJ, Oliver JL, Marín A and Medina JR (1990) The general stochastic model of nucleotide substitution. J Theor Biol 142:485-501.

Ronquist F and Huelsenbeck JP (2003) MrBayes 3: Bayesian phylogenetic inference under mixed models. Bioinformatics 19:1572-1574.

Rosa RS (1985) A systematic revision of the South American freshwater stingrays (Chondrichthyes, Potamotrygonidae). Ph.D. Thesis, The College of William and Mary, Williamsburg.

Rosa RS and Carvalho MRd (2007) Família Potamotrygonidae. In: Buckup PA, Menezes NA and Ghazzi MSA (eds) Catálogo das Espécies de Peixes de Água Doce do Brasil. Museu Nacional, Rio de Janeiro, pp 17-18. 
Rozas J, Sánchez-DelBarrio JC, Messenguer X and Rozas R (2003) DnaSP, DNA polymorphism analyses by the coalescent and other methods. Bioinformatics 19:2496-2497.

Rubinoff D (2006a) Utility of mitochondrial DNA barcodes in species conservation. Conserv Biol 20:1026-1033.

Rubinoff D (2006b) DNA barcoding evolves into the familiar. Conserv Biol 20:1548-1549.

Sambrook J, Fritsch EF and Maniatis T (1989) Molecular Cloning: A Laboratory Manual. v. 1. 2nd ed. Cold Springs Harbor Laboratory Press, Cold Springs Harbor.

Sanderson M (1997) A nonparametric approach to estimating divergence times in the absence of rate constancy. Mol Biol Evol 14:1218-1231.

Sanderson MJ (2002) Estimating absolute rates of molecular evolution and divergence times: A penalized likelihood approach. Mol Biol Evol 19:101-109.

Schluter D (2000) The Ecology of Adaptive Radiation. Oxford University Press, Oxford, 288 pp.

Shimodaira H and Hasegawa M (1999) Multiple comparisons of log-likelihoods with applications to phylogenetic inference. Mol Biol Evol 16:1114-1116.

Swofford DL (2002) PAUP*. Phylogenetic Analysis Using Parsimony (* and Other Methods), Beta Version 4b10. Sinauer Associates. Sunderland.

Thompson JD, Higgins DG and Gibson TJ (1996) CLUSTAL W: Improving the sensitivity of progressive multiple sequence alignment through sequence weighting, position specific gap penalties and weight matrix choice. Nucleic Acids Res 22:4673-4680.
Thorne JL and Kishino H (2002) Divergence time and evolutionary rate estimation with multilocus data. Syst Biol 51:689702.

Thorson TB, Brooks DM and Mayes MA (1983) The evolution of freshwater adaptation in stingrays. Nat Geo Soc Res Reports 15:663-694.

Toffoli D (2006) História evolutiva de espécies do gênero Potamotrygon Garman, 1877 (Potamotrygonidae) na Bacia Amazônica. M.Sc. Thesis, Instituto Nacional de Pesquisas da Amazônia and Universidade Federal do Amazonas, Manaus.

Turner GF, Seehausen O, Knight ME, Allender CJ and Robinson RL (2001) How many species of cichlid fishes are there in African lakes? Mol Ecol 10:793-806.

Verheyen E, Salzburger W, Snoeks J and Meyer A (2003) Origin of the superflock of cichlid fishes from Lake Victoria, East Africa. Science 300:325-329.

Vinson C, Gomes G, Schneider H and Sampaio I (2004) Sciaenidae fish of the Caeté River estuary, Northern Brazil: Mitochondrial DNA suggests explosive radiation for the Western Atlantic assemblage. Genet Mol Biol 27:174-180.

Ward RD, Zemlak TS, Innes BH, Last PR and Hebert PDN (2005) DNA barcoding Australia's fish species. Phil Trans R Soc Lond B, Biol Sci 360:1-11.

\section{Internet Resources}

Consortium for the Barcode of Life (CBOL), http://barcoding.si.edu/ (April 1, 2007).

Laboratório de Evolução e Genética Animal (LEGAL), http://www.evoamazon.net/.

Associate Editor: Cláudio Oliveira

License information: This is an open-access article distributed under the terms of the Creative Commons Attribution License, which permits unrestricted use, distribution, and reproduction in any medium, provided the original work is properly cited. 